\title{
Associação entre fatores sociodemográficos e a prevalência do aleitamento materno exclusivo no primeiro mês de vida
}

\author{
Marcela Martins Soares, Mariane Alves Silva, Poliana Cristina de Almeida Fonsêca, Sarah \\ Aparecida Vieira, Raquel Maria Amaral Araújo, Sylvia do Carmo Castro Franceschini
}

\section{Resumo}

O leite materno é considerado alimento completo e ideal para a alimentação ótima das crianças. Diante disso, a Organização Mundial da Saúde recomenda que o mesmo seja ofertado de forma exclusiva até o sexto mês e de forma complementar até os 2 anos ou mais. Entretanto, existem diversos fatores socioeconômicos que podem influenciar a execução desta prática, dentre os quais se destacam a baixa escolaridade, idade materna, condições de parto ou falta de informação decorrente a não realização do pré-natal, pouca disponibilidade de tempo e, ou, falta de apoio psicológico e emocional, fato estes que justificam a realização deste trabalho. Avaliar a associação entre fatores sociodemográficos e a prevalência do aleitamento materno exclusivo no primeiro mês de vida. Estudo transversal com 226 crianças de Viçosa-MG. Durante entrevistas realizadas com os responsáveis foi aplicado um questionário semiestruturado contendo questões referentes à situação sociodemográfica. Para a classificação do tipo de aleitamento materno (exclusivo, predominante, complementar e misto), utilizou-se as definições adotadas pelo Ministério da Saúde. As análises foram realizadas utilizando o software Stata versão 10.0. Na análise bivariada estimou-se a razão de prevalência e intervalo de confiança pela Regressão de Poisson com variância robusta, sendo as variáveis com valor de $\mathrm{p}<0,20$ incluídas no modelo múltiplo. A prevalência de aleitamento materno exclusivo no primeiro mês foi de $45,6 \%$. Após a análise múltipla, o chefe da família e a sua escolaridade se associaram com o aleitamento materno exclusivo, de modo que filhos de chefe com maior escolaridade ( $\mathrm{RP}=0,55$; IC95\%:0,42 - 0,73) apresentaram menor prevalência de aleitamento materno exclusivo no primeiro mês de vida. Conclui-se que a prevalência de aleitamento materno exclusivo no primeiro mês de vida é baixa. Quando o chefe da família é o marido há maior prevalência do aleitamento materno de forma exclusiva no primeiro mês, fato este que pode estar relacionado a não preocupação materna em voltar a trabalhar para sustentar a família. No que se refere à escolaridade, percebeu-se que quando esta é maior ou igual a nove anos, o aleitamento materno exclusivo neste período é mais frequente, tal situação mostra a importância do conhecimento familiar sobre os benefícios da prática do aleitamento materno, o qual torna-se mais acessível quando há maior escolaridade.

Descritores: Fatores Sociodemográficos; Aleitamento Materno; Lactente. 